\title{
Perceived Benefits of Adopting Sustainable Tourism Business Practices: A View from Guest Houses in the Eden District Municipality
}

\author{
Dr T. Ramukumba, Prof IW Ferreira
}

Faculty of Business and Economic Sciences, Department of Tourism. Nelson Mandela Metropolitan University

\begin{abstract}
Companies that want to stay competitive in the future must integrate sustainability practices into their business strategies. Competitiveness and sustainability are important to the survival of the company, and thus companies must view the call to sustainability as a strategic opportunity rather than as a restriction to creating value.

This article presents the results of an investigation into the perceived benefits of adopting and implementing sustainable business practices by guest houses in the Eden District Municipality (EDM). The main objective of the study was to investigate what potential benefits guest houses are seeking to gain by adopting these sustainable tourism practices. The research used a quantitative methodology using a questionnaire as a survey instrument. Of the 250 guest houses listed in the EDM database, 128 (51.2\%) agreed to participate. The main findings of the study indicate that guest houses indeed seek various benefits in adopting and implementing sustainable tourism business practices. Rather surprisingly, the findings of the study infer that the benefits of 'sustainable tourism practices' as perceived by the guest house owners, managers and locums in the sample were related to non-economic benefits. This is confirmed by 56.3\% of respondents who stated that they adopt and implement sustainable tourism practices for the benefit of environmental protection. The results show a positive trend towards attaining sustainability in the tourism industry by accommodation providers which augers well for the future of the industry.
\end{abstract}

Keywords: Guest houses, Sustainable business practices, Sustainable tourism, Tourism industry

\section{INTRODUCTION}

The term 'sustainable development' was first defined in the 1980's in the Brundtland report which defined it as development that meets the needs of the present without compromising the ability of future generations to meet their own needs. The tourism industry has also embraced the concept of sustainable development, but its definition is still widely discussed and researched (Sharpley, 2000). The difficult definition and the complexity involved have been highlighted as barriers to translate the concept of sustainable development into precise actions and sustainable business practices for the tourism industry. Nevertheless, the tourism industry and in particular the accommodation sector has acknowledged the critiques about their contribution to the unsustainable depletion of resources (Mowforth \& Munt, 2009). Through voluntary initiative and self-regulation the industry intends to encourage the implementation of sustainable business practices. Whether this motivation is based on a sense of moral responsibility, companies' self-interest or simply to prevent statutory regulation is debatable (Bramwell \&Alletorp, 2001). As attitudes are said to be related to behaviour and actions, the attitudes of business managers toward sustainability and responsibility for sustainable development are subject to frequent investigations by researchers. So far, previous research showed that there is no agreement whether the main responsibility for sustainable development should lie with the public or the private sector (Bramwell \& Alletorp, 2001). Ideologically a participatory approach, including not only the industry and government but also the tourists and host community would create a more holistic understanding of sustainable tourism (Manning, 1999). Nevertheless, the communication between public and private sector is often ineffective (Dewhurst \& Thomas, 2003). Within the wider literature the awareness and especially the demand of guests for sustainable business practices in the accommodation industry is frequently debated. Although 'green consumerism' is said to be increasing, business owners report no rise in actual consumer demand (Sloan, Legrand \& Chen, 2009). 


\section{Dr T. Ramukumba \& Prof IW Ferreira}

Liu (2003) has observed that sustainable tourism became a critical research topic in tourism management (at both micro and macro levels) in the 1980s. Continuous efforts have been made to formulate suitable, sustainable tourism programs with different conditions and different levels in different countries. Most researchers agree that a successful sustainable tourism program requires support and participation from the government, local communities, visitors, tourism businesses, and other influences such as media and international forces, as well as certain non-governmental organizations (Dewhurst and Thomas, 2003; Liu, 2003). However, Dewhurst and Thomas (2003) and Liu (2003) pointed out that successful examples of sustainable tourism often begin at the micro or firm level. Thus, a tourism firm's voluntary participation can play a crucial role in the success of a sustainable tourism program (Rangel, 2000).

The main motive for the implementation of sustainable business practices is based on the business managers' or the corporations' philosophy and closely linked to the possibility of saving costs (Landrum \& Edwards, 2009; Hitchcock \& Willard, 2009). But positive public relations and higher employee commitment and satisfaction were also mentioned as important benefits (Hitchcock \& Willard, 2009; Baum, 2006). However, the majority of previous studies as well as the measures taken by businesses focus primarily on the environmental dimensions of sustainability and therefore fail to acknowledge the holistic principle of sustainable development. The socio-cultural, environmental and economic realms are interdependent and the aim of a sustainably managed business should be the optimisation of all three (Hitchcock \& Willard, 2009; Elkington, 2004). Whether or not these are understood by guest house accommodation owners/ managers may be an interesting field of research. Therefore the main aim of this article was to investigate the perceived benefits of adopting sustainable tourism business practices by guest houses in the Eden District Municipality (EDM).

\section{SUSTAINABILITY IN THE TOURISM INDUSTRY}

The tourism industry is one of the largest single industries worldwide which has been criticised for its unsustainable practices such as the exploitation of the environment and local population; little commitment to particular destinations; control through large transnational corporations; unsustainable planning of physical elements, little action for awareness-raising and implementation of sustainable initiatives only for good publicity and reducing costs (Mowforth \& Munt, 2009). The industry has also been accused of its strong motive of short-term profit maximisation instead of long-term sustainability (Mowforth\& Munt, 2009). Bansal (2002: 124) argues that "organizational goals are tied to economic performance, not environmental performance or social equity" and that this orientation is understandable given that a firm's time horizon is considerably shorter than society's". Nevertheless, there are many examples of good environmental practice allied with profitability (Mowforth \& Munt, 2009).

\section{Sustainable Business Practices}

Based on the Brundtland definition of sustainable development, Landrum and Edwards (2009: 4) define a sustainable business as "one that operates in the interest of all current and future stakeholders in a manner that ensures the long-term health and survival of the business and the associated economic, social, and environmental systems". Businesses solely focusing on reducing their environmental impact are referred to as 'green businesses' whereas a sustainable business would focus on all three dimensions of sustainability, which have often been referred to as 'triple bottom line'. The realms are intimately intertwined and their interdependencies need to be understood (Hitchcock \& Willard, 2009; Elkington, 2004). The limitation to the environmental dimension has been criticized by several authors about the attempt of the tourism industry, in particular the accommodation industry, to become 'sustainable' (Font \& Harris, 2004).

However, taking environmental initiatives can be the first step towards sustainability according to the four-step model for sustainable development in tourism enterprises by Kernel (2005). The first steps are mainly concerned with developing environmentally cleaner processes and environmental management practices. The consequent and final steps challenge organisations to go further and include social and ethical aspects as well as integration in the community (Kernel, 2005). Similarly, Dunphy, Griffiths and Benn's (2007) sustainability phase model defines distinct steps organisations can take to reach sustainability. The final phase is called 'the sustaining corporation' where the ideology of sustainability is internalised with a fundamental commitment to facilitate ecological viability of the planet and contribute to equitable social practices and human fulfilment. According to 
Dunphy et al. (2007) this stage has not been reached by any organisation for the time being. Many businesses appear to be in the initial phase and need to continue their efforts to combine the ecologic, environmental and socio-cultural dimension of sustainability.

\section{Strategic Implementation of Sustainable Business Practices}

Successful implementation of sustainable business practices can only be reached when the holistic principle of sustainability is understood and integrated into the strategic planning of the business. If sustainability initiatives are seen as add-ons or as another performance variable, the full benefits of sustainable business practices will not be reached (Larson et al., 2000). Strategic sustainability represents a commitment demonstrated by top management that moves beyond compliance and efficiency to avoid risks and minimize costs (Dunphy et al., 2007). The integration of sustainability into strategic planning will also require businesses to develop a more long-term focus and thus help them to examine threats and opportunities. It is essential that sustainability is perceived as a companywide goal that incorporates every aspect of business and its relationships. This requires a system thinking that everything is related in some way and each part and each person in the business can contribute towards more sustainability (Landrum \& Edwards, 2009) Therefore a bottom-up approach as well as top-down approaches are required involving goals, tactics and budgets which should be reviewed and updated regularly. Also the process and performance needs to be regularly monitored and audited (Blackburn, 2007). Cooper et al. (2008: 363) who stated that "in some countries tourism organisations, for instance, in Scotland, the Green Tourism Business Scheme encourages to introduce environmental impact measures which are designed to lower their impact of their business on the environment. According to Cavagnaro and Gehrels (2009) as it is generally understood, sustainability requires the integration of economic, environmental, and social components in policy making and business operations

\section{BenEFits OF THE IMPLEMENTATION OF SUSTAinable BuSiness PraCticeS}

The moral obligation or pure desire to contribute to society might be the reason for adopting sustainable business practices for some businesses (Tzschentkeet al., 2004); but for many the business case for sustainability and the benefits related to sustainable business practices tie the commercial interest of business to the goals of society (Miller \& Twining-Ward, 2005). Below are some of the benefits of implementing sustainable business practices by guest houses.

\subsection{Cost Reduction}

The most cited benefit of sustainable business practices is the reduction of costs (Landrum \& Edwards, 2009; Bohdanowicz et al., 2004; Hitchcock \& Willard, 2009). Tzschentkeet al., (2004) declare it as the prime motive behind introducing environmental initiatives. In particular the rising costs for water, energy and waste disposal led many businesses to look for alternatives. Operational measures are for example recycling systems, using recycled materials, installing water-saving devices, using low energy light bulbs, energy-conservation measures such as insulation or solar-powered water heating systems. These initiatives focus exclusively on the environmental dimension of sustainable business practices (Swarbrooke, 1999). There is a lack of literature and research about cost saving possibilities related to the socio-cultural and economic dimension of sustainability.

\subsection{Public Relations}

Sustainable business practices can also bring benefits to a company in terms of positive public relations and improved guest houses image with shareholders and local community. These benefits can differentiate the business from its competitors and can be the source of competitive advantages and new market opportunities (Hitchcock \& Willard, 2009; Landrum \& Edwards, 2009; Swarbrooke, 1999). Kirk's (1998) findings reveal that public relation benefits had the most positive attitude ratings, followed by 'improved relation with the local community' and 'marketing'. The analysis shows interesting associations with the guest houses characteristics. Large guest houses, guest houses with a classification between 3 and 5 stars and chain guest houses were more likely to see positive public relation benefits (Kirk, 1998) than small, 2 star classified, independent guest houses.

\subsection{Employee Satisfaction}

Through sustainable human resource management employees are more likely to feel adequately rewarded, valued, and proud of their work and have a more positive self-image (Baum, 2006). Service quality but also health and productivity are likely to improve through more sustainable developments 
and business practices (Butler, 2008). The move towards sustainability requires a positive change in corporate culture. In this context, culture can be described as the hidden driving force of people's behaviour both inside and outside organisations.

Cultural beliefs, thinking and behaviour need to be consistent with the concept and values of sustainable business practices to make efforts successful (Doppelt, 2003; Schein, 2009). Sustainable human resource management and a sustainable corporate culture can help the company to attract and retain the best employees which at present is a serious problem in the tourism and hospitality industry (Hitchcock \& Willard, 2009).

\subsection{Consumer Demand}

Consumer demand is the most controversial benefit of sustainable business practices. Environmental and social concerns increasingly influence customer behaviour but so far it is debatable if this 'green' consumerism has reached the tourism industry (Miller \& Twining-Ward, 2005). Once more the difficulties in defining sustainable tourism and sustainable business practices force consumers to base their choice on individual judgement and limited knowledge. Sustainable tourism products are often not readily available and clearly specified. Consequently greater information and disclosure about the impacts of the products is necessary (Miller \& Twining-Ward, 2005). Many researchers argue that the increased awareness for general societal issues will ultimately lead to a rise in demand for sustainable travel and tourism products (Bohdanowicz \& Martinac, 2003; Sloan et al., 2009). However, although people might be aware of the negative impacts of tourism, they are not willing to pay more for environmentally-friendly products (Dodds\&Joppe, 2003). Business owners are unconvinced that consumers will be attracted by a business's environmental performance and more research is required to determine the actual consumer demand for sustainable business practices in the accommodation industry (Dewhurst \& Thomas, 2003; Sloan et al., 2009). Also, there remains a lack of knowledge and awareness of the industry's leaders of the environmental, economic, and social benefits gained through sustainability. Without proper education and motivation to understand the benefits and costs, sustainability is far from becoming the industry standard (Bader, 2005).

\section{Study Area}

This study was based and concentrated on the region known as the Eden District Municipality (EDM). The EDM is located along the south-eastern coast of the Western Cape Province. It stretches roughly for 350 kilometres along the Indian Ocean, from the Bloukrans River in the east, to Wits and at the Breede river mouth in the west (see Figure 1). The Eden district municipality covers the Kannaland, Mossel Bay, George, Oudtshoorn, Plettenberg Bay, Hessequa and Knysna local municipalities (EDM, 2011).

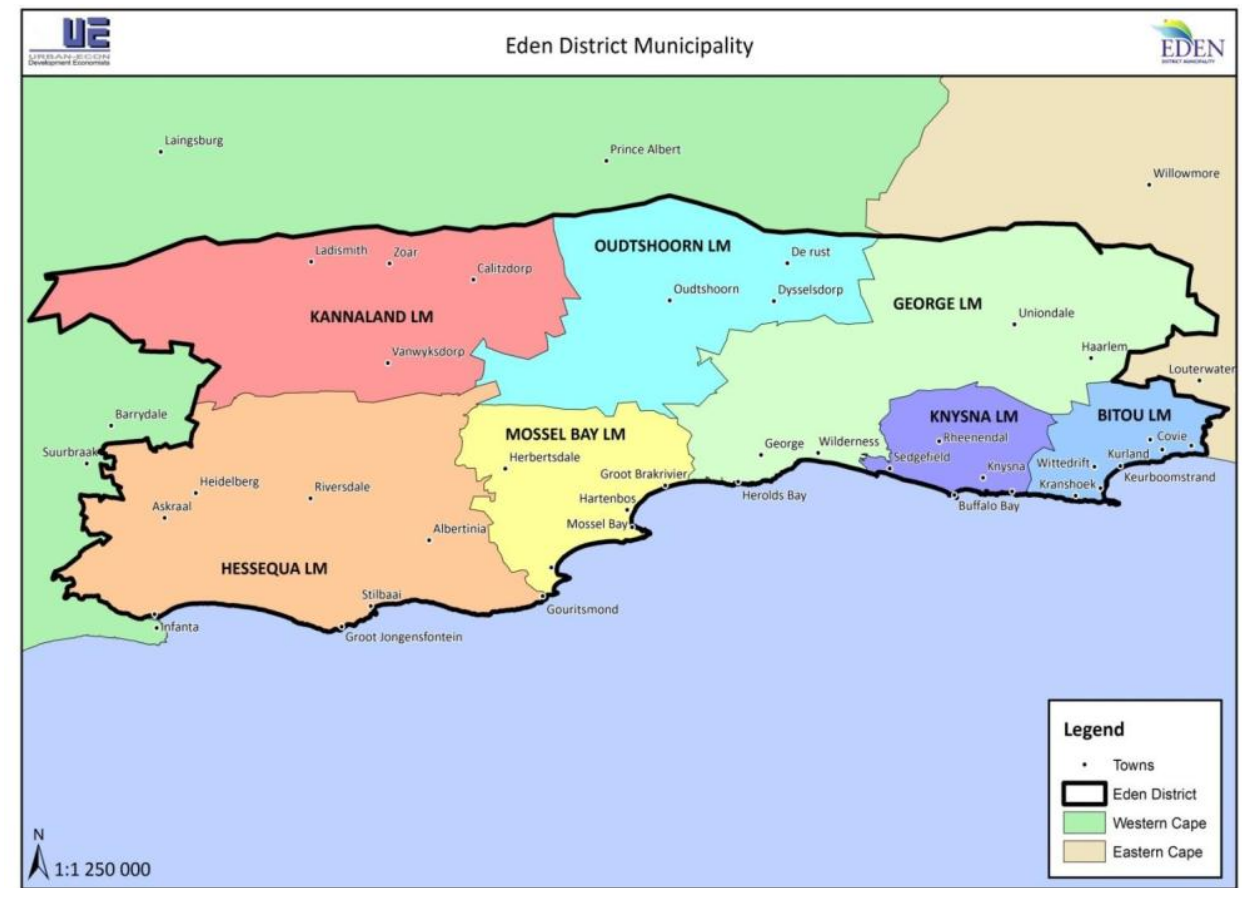

Figure1. Eden District Municipality map, South Africa (EDM, 2011) 


\section{METHODOLOGY}

A questionnaire survey of guest house establishments in the region was undertaken to assess the sustainable tourism business practices by the guest houses in the EDM. The questionnaire obtained information relating to the importance of the environment to the tourism industry, the adoption of sustainable practices and the characteristics of the respondents (position of the person completing the questionnaire, owner's involvement in running the business, number of years of business existence, and type of business. The sampling strategy was based on the 'EDM database' which detailed accommodation units registered with the EDM Local Economic Development and Tourism Department. Initially, the guesthouses listed were contacted by an email in order to ascertain their willingness to take part in the survey.

Of the 250 guest houses listed in the EDM database, 128 (51.2\%) agreed to participate. The survey took place over the period 15 June to 18 July 2014. This period proved to be advantageous because it was low season and guest house managers, owners and locums could afford the time to answer questions.

\section{Results}

This section provides the findings of the study and gives a general picture of the perceived benefits of adopting and implementing sustainable business practices by guest houses in the Eden District Municipality.

Table1. Perceived Benefits of Adopting Sustainable Tourism Practices

\begin{tabular}{|l|l|l|l|l|l|}
\hline & Strongly agree & Agree & Neutral & Disagree & Strongly disagree \\
\hline Improved business prospects & $41 \%$ & $45 \%$ & $13 \%$ & $0.8 \%$ & $0 \%$ \\
\hline Savings on expenditure & $39.3 \%$ & $45.1 \%$ & $12.3 \%$ & $1.6 \%$ & $1.6 \%$ \\
\hline Improved image & $43.4 \%$ & $43.3 \%$ & $11.5 \%$ & $0.8 \%$ & $0 \%$ \\
\hline New clientele & $43.3 \%$ & $38.5 \%$ & $14.8 \%$ & $1.6 \%$ & $0.8 \%$ \\
\hline Improved customer perception & $43.4 \%$ & $45.1 \%$ & $10.7 \%$ & $0.8 \%$ & $0 \%$ \\
\hline Increased environmental protection & $56.3 \%$ & $35.3 \%$ & $8.4 \%$ & $0 \%$ & $0 \%$ \\
\hline
\end{tabular}

The results as shown in table 1, rather surprisingly, infer that the benefits of 'sustainable tourism' as perceived by the guest house owners, managers and locums in the sample were related to noneconomic factors. More than half of respondents (56.3\%) recognised the contribution to environmental protection, while $43.4 \%$ pointed to the potential improvements in customer perceptions and improved image with $43.3 \%$ pointed to the benefits of new clientele. The benefit of expenditure savings (39.3\%) was perceived to be much less important compared to those mentioned above even though $45.1 \%$ agreed that they adopt and implement sustainable tourism practices for savings on expenditure. Indeed, 56.3\% of guest houses thought that sustainable practices would offer no financial reward. Therefore, it appeared that the majority of businesses recognised the potential contribution of sustainable tourism practices to the protection of the resource base, whilst also recognising that the approach would benefit their business in a way that would be worthwhile commercially as $45.1 \%$ did agree on savings on expenditure. These results are in line with Cooper et al. (2008: 363) who stated that "in some countries tourism organisations, for instance, in Scotland, the Green Tourism Business Scheme encourages to introduce environmental impact measures which are designed to lower their impact of their business on the environment.

\section{Discussion AND CONCLUSION}

Based on the views of Bader (2005) who stated that the hospitality industry becoming the greatest example that shows that sustainable practices within a business are crucial for its long-run success, the findings of this study concurs with the view that as costs for energy, water, amongst others are rising, guest houses are more or less forced to act economically, environmentally and socially responsible. On the other side, Cavagnaro and Gehrels (2009) argue that the hospitality industry is in general not really aware of sustainability. In particular, only few hospitality businesses implemented sustainable practices in their daily routines (Bader, 2005). A reason for this could be the unawareness of the public and industry that sustainable practices bring benefits to the surrounding society economy and environment and of course to the guest houses business at the same time. Nevertheless, this will change in the next time due to the given reasons of increased costs and changing demand, in particular 


\section{Dr T. Ramukumba \& Prof IW Ferreira}

the demand of greener products and services. The statements above are supported by 56.3\% respondents who strongly agreed that they adopt and implement sustainable tourism practices for environmental protection purposes. Guest houses are depended on their surrounding environment, because this is the main reason why people come to a certain area. In other words, guest houses rely on their immediate surroundings and therefore, they should preserve it in order to exist in the long-run (Bader, 2005).

Since the end of the 1990s, more and more guest houses have implemented sustainable practices. The main goals were since then various, some want to save costs, others want to promote themselves and even others wanted to set an ethical statement. (Cavagnaro \&Gehrels, 2009).However, Cavagnaro \&Gehrels (2009) argue that is seems to be easier for smaller businesses to set up sustainable commitments. A reason for this could be that there might be a better communication and coordination between the various departments. Guest houses have many possibilities to act sustainable. These practices bring various benefits to the business and the environment. The most obvious benefits of sustainable practices within a business have a financial character. Previous research revealed a huge amount of costs can be reduced by using energy-saving measures. For example, energy-saving light bulbs can be installed. Furthermore, guest houses can make use of sensors and timers for light instalments which ensure that the light is only switched on in areas/rooms when it is needed. Moreover, employees of the guest houses could be remembered to turn off lights when they are leaving a room. Key tag controlled switches for guest houses rooms are another very effective action. This means that the key card for the door is simultaneously the card who switches on the electricity including air condition in the room. This ensures that guests do not have the chance to leave the light or air condition turned on when they are leaving their rooms. The results of this study did not place financial savings as the highest perceived benefit of adopting sustainable tourism business practice by the guest house based on those who strongly agreed with the statement on savings on expenditure. Savings on expenditure was rated lower than environmental protection (56.3\%), improved customer perception (43.4\%), improved image (43.4\%), acquiring new clientele (43.3\%), and improved business prospects (41\%). In general, the results of the study infer that guest houses in the EDM are adopting and making uses of sustainable business practices for various benefits.

\section{REFERENCES}

Bader, E.E. (2005). Sustainable hotel business practices. Journal of Retail \& Leisure Property, 5(1) 70-77.

Bansal, P. (2002) 'The Corporate Challenges of Sustainable Development', The Academy of Management Executive, 16(2) 122-131.

Baum, T. 2006. Human resource management for tourism, hospitality and leisure: an international perspective, London: Thomson.

Blackburn, W.R. (2007) The sustainability handbook - The complete management guide to achieving social, economic and environmental sustainability, London: Earthscan.

Bramwell, B. and Alletorp, L. 2001. 'Attitudes in the Danish Tourism Industry to the Roles of Business and Government in Sustainable Tourism', International Journal of Tourism Research, (3) $91-103$.

Bohdanowicz, P.; Zanki-Alujevic, V. and Martinac, I. (2004) 'Attitudes towards Environmental Responsibility among Swedish, Polish and Croatia Hoteliers', Conference Proceedings, BEST Tourism Think Tank IV, Esbjerg, Denmark.

Bohdanowicz, P.,Simanic, B. and Martinac, I. (2005) 'Sustainable Hotles - Environmental Reporting According to Green Globe 21, Green Globes Canada /GEM UK, IHEI Benchmarkhotel and Hilton Environmental Reporting', Conference Proceedings, The 2005 World Sustainable Building Conference, Tokyo.

Butler, J. (2008) 'The Compelling "Hard Case" for "Green" Hotel Development', Cornell Hospitality Quarterly, 49(3) 234-244.

Butler, R.W. (1999), "Sustainable Tourism: A State-of-art Review”, Tourism Geographies, (1) 7-25.

Cavagnaro., E and Gehrels., S.A (2009) Sweet and Sour Grapes: Implementing Sustainability in the Hospitality Industry - A Case Study, Journal of Culinary Science \& Technology, 7(2-3) 181195. 
Cooper, C., Fletcher, J., Fyall, A., Gilbert, D., \& Wanhill, S. (2008). Tourism: principles and practice. Essex, UK: Pearson Education Limited

Dewhurst, H., and R. Thomas (2003), "Encouraging Sustainable Business Practices in a Nonregulatory Environment: A Case Study of Small Tourism Firms in a UK National Park", Journal of Sustainable Tourism, 11(5) 383-403.

Doppelt, B. (2003) Leading Change toward Sustainability: A Change-Management Guide for Business, Government and Civil Society, Sheffield: Greenleaf Publishing.

Doppelt, B. (2003) Leading Change toward Sustainability: A Change-Management Guide for Business, Government and Civil Society, Sheffield: Greenleaf Publishing.

Dunphy, D.; Griffiths, A. and Benn, S. 2007. Organizational change for corporate sustainability - A guide for leaders and change agents of the future, 2nded, London: Routledge.

Elkington, J. 2004. 'Enter the Triple Bottom Line' in Henriques, A. and Richardson, J. (ed.) The Triple Bottom Line: Does it all add up? London: Earthscan. Fachverband.

Font, X. and Harris, C. (2004) 'Rethinking standards from green to sustainable', Annals of Tourism Research, 31(4) 986-1007.

Hitchcock, D. and Willard, M. 2009. The business guide to sustainability - Practical strategies and tools for organizations. 2nded, London: Earthscan.

Kirk, D. (1998) 'Attitudes to environmental management held by a group of hotel managers in Edingburgh', Hospitality Management, (17) 33-47.

Landrum, N.E. and Edwards, S. 2009. Sustainable Business: An Executive's Primer, New York: Business Expert Press.

Larson, A.L.; Olmsted-Teisberg, E. and Johnson, R.R. (2000) 'Sustainable Business: Opportunity and Value Creation', Interfaces - Sustainable business, 30(3) 1-12.

Liu, Z. (2003), "Sustainable Tourism Development: A Critique", Journal of Sustainable Tourism, 11(6) 459-475.

Manning, T. 1999. Indicators of tourism sustainability', Tourism Management, (20) 179-181.

Miller, G.A. and Twining-Ward, L. (2005) Monitoring for a sustainable tourism transition: the challenge of developing and using indicators, Wallingford: Cabi.

Mowforth, M. and Munt, I. 2009. Tourism and Sustainability: New Tourism in the Third World. 3rd ed. London: Routledge.

Rangel, J.R. (2000), Does It Pay To Be Green In The Developing World? Participation in Costa Rican Voluntary environmental program and its impact on hotels' competitive advantage, Unpublished Doctoral Dissertation, Duke University.

Schein, E.H. (2009) The Corporate Culture Survival Guide, San Francisco: Jossey-Bass.

Sharpley, R. 2000. Tourism and Sustainable Development: Exploring the Theoretical Divide', Journal of Sustainable Tourism, 8, (1), 1-19.

Sharpley, R. and Telfer D. J. 2002. Tourism and development: concepts and issues. Channel View Publications: Clevedon.

Sloan, P.; Legrand, W. and Chen, J.S. 2009. Assessing Hoteliers' Awareness and Perception of Environmental Initiatives. Conference Proceedings, EuroCHRIE Congress, Bad Honnef, Germany.

Swarbrooke, J. 1999. Sustainable tourism management. London: CABI Publishing.

Tzschentke, N.; Kirk, D. and Lynch, P.A. (2004) 'Reasons for going green in serviced accommodation establishments', International Journal of Contemporary Hospitality Management, 16(2) 116-124. 